Fettvermehrung, aber keine Adipositas

\title{
Das Lipödem: nicht nur ein kosmetisches Problem
}

\author{
Das Lipödem - ein durchaus häufiges Krankheitsbild bei Frauen - geht mit einer \\ erheblichen Beeinträchtigung der Lebensqualität einher. Nicht selten wird es als \\ Adipositas fehlgedeutet. Die Erkrankung ist zwar nicht heilbar, aber die Liposuktion \\ ist in Kombination mit konservativen Maßnahmen eine segensreiche Therapie.
}

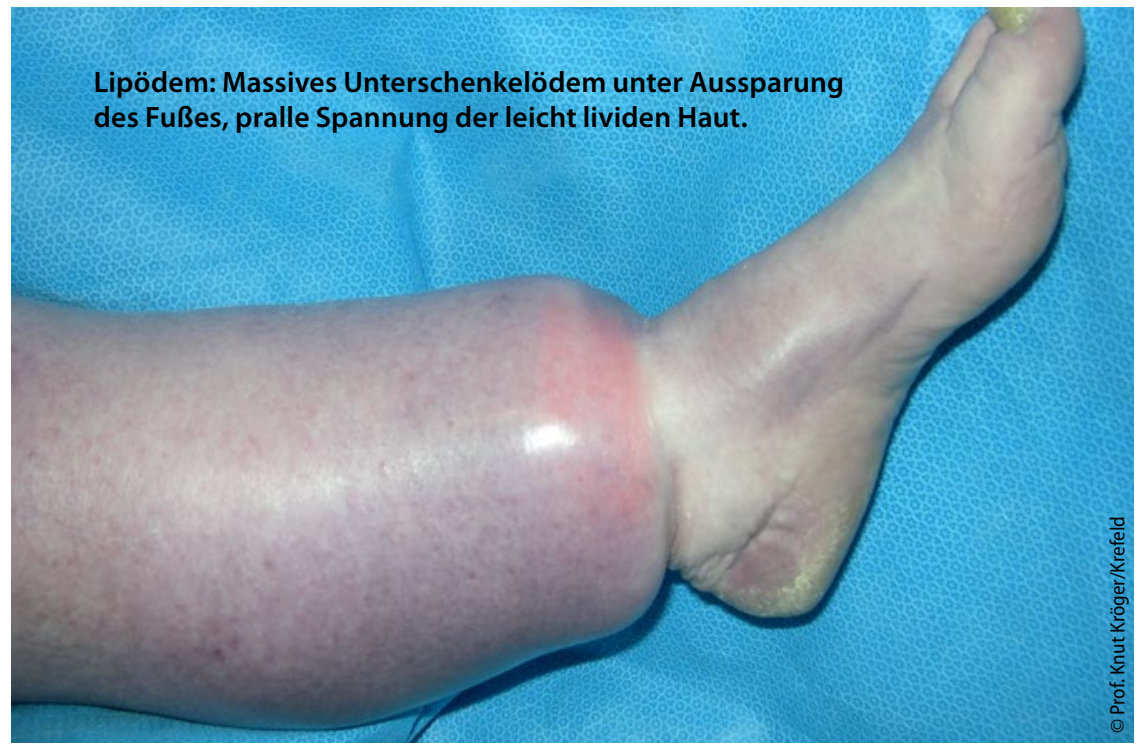

_ Das Lipödem ist eine typische Blickdiagnose. „Viele betroffene Patientinnen klagen jedoch über ein fehlendes Bewusstsein bei ihren Ärzten“, so Dr. Birgit Wörle, Meggen. Das Krankheitsbild werde häufig gar nicht als solches erkannt und/oder als Adipositas fehlinterpretiert. Deshalb wird den Frauen nicht selten eine Gewichtsreduktion empfohlen, was aber trotz guter Bemühungen keinen oder nur einen geringen Erfolg hat, gelegentlich bei jüngeren Patientinnen sogar $\mathrm{zu}$ einer Anorexie führen kann. „Die Patientinnen leiden sehr, sie klagen über ein im Tagesverlauf zunehmendes Schweregefühl und auch über Schmerzen in den Beinen“, so Wörle.

\section{Lipohypertrophie oder Lipödem?}

Typisch für das Lipödem ist eine Disproportion bei einem relativ schlanken Oberkörper und z.T. massiver Fettge- websvermehrung an den Beinen, seltener auch an den Armen. Zusätzlich bilden sich Hämatome, Zellulite und Dehnungsstreifen. Abzugrenzen ist das Lipödem von der Lipohypertrophie, die ein ausschließlich ästhetisches Problem ohne eigentlichen Krankheitswert darstellt. Bei einer solchen „Reithosen-Problematik“ findet sich eine ausgeprägte polsterartige Vermehrung des Fettgewebes im Bereich der äußeren Oberschenkel, allerdings ohne weitere Beschwerden wie Spontanoder Berührungsschmerz, Hämatomneigung oder Schwellungen. Die Lipohypertrophie zeigt im Gegensatz zum Lipödem auch keine Progredienz in Richtung sekundäres Lipolymphödem.

\section{Leitlinie empfiehlt Liposuktion}

Für die Therapie des Lipödems wurde 2015 eine S1-Leitlinie herausgegeben. Danach gilt die Fettabsaugung, sprich die Liposuktion in einer Tumeszenz-Lokalanästhesie, als eine etablierte risikoarme operative Behandlungsmethode. „Sie ist heute neben der kombinierten physikalischen Entstauungstherapie mit Kompressionsstrümpfen und manueller Lymphdrainage ein fester Bestandteil des Therapiekonzepts“, so Wörle. Bei Übergewicht sollte auch eine Gewichtsreduktion angestrebt werden.

\section{Keine Heilung, aber Erleichterung}

Mit diesen Maßnahmen kann die Erkrankung zwar nicht geheilt werden, aber bei vielen Frauen verbessern sich Symptomatik und somit die Lebensqualität wesentlich. Die ästhetische Verbesserung der Körperform steigere auch das Selbstwertgefühl der Frau, so Wörle. In Einzelfällen könne nach einer Liposuktion auf die konservative Begleittherapie mit flach-gestrickten Kompressionsstrümpfen der Klasse II-III und manuelle Lymphdrainage sogar ganz verzichtet werden. Die Liposuktion müsse jedoch mit höchstem ästhetischen Anspruch durchgeführt werden, sie sei kein „Übungsmodell“ für unerfahrene Operateure ohne ästhetisches Empfinden.

Bei der Kostenübernahme durch die Krankenkassen kann es allerdings Probleme geben, da eine endgültige Entscheidung des G-BA hinsichtlich der Nutzenbewertung bisher noch nicht vorliegt. Doch wenn konservative Maßnahmen keinen Erfolg bringen und der Befund progredient ist, sollte man sich im Einzelfall bei der zuständigen Kasse um eine Kostenübernahme bemühen.

\section{Dr. Peter Stiefelhagen}

- Quelle: 25. Fortbildungswoche für praktische Dermatologie und Venerologie, 25.7.2016 in München 